\title{
Yaşlı hastalarda endoskopik retrograd kolanjiopankreatografi işleminin etkinlik ve güvenilirliği
}

\author{
The efficacy and safety of endoscopic retrograde cholangiopancreatography in elderly patients
}

Mustafa ÇELIK, Altay KANDEMIR, Mahmut ARABUL, Emrah ALPER, Hüseyin Sinan AKAY, Zafer BUYRAÇ, Fatih ASLAN, Belkıs ÜNSAL

Atatürk Eğitim ve Araştırma Hastanesi, Gastroenteroloji Kliniği, Izmir

\begin{abstract}
Giriş ve Amaç: Yaşlı hastalarda kullanımı giderek artan endoskopik retrograd kolanjiopankreatografi işleminin, etkinliği ve güvenilirliğine yönelik s1nırlı sayıda çalıșma mevcuttur. Bu çalıșmada yaşlı hastalarda endoskopik retrograd kolanjiopankreatografi işleminin etkinliği, güvenilirliği ve işlem başan1 oranlarını değerlendirdik. Gereç ve Yöntem: Izmir Atatürk Eğitim ve Araştırma Hastanesi Gastroenteroloji Kliniğinde, 2006-2010 yılları arasında endoskopik retrograd kolanjiopankreatografi yapılan hastalar retrospektif olarak değerlendirildi. Hastalar 45-65 yaș, 65-80 yaș arası ve 80 yaș üzeri olacak şekilde 3 gruba ayrıldı ve gruplar tanı, işlem etkinliği, işlem başarısı, anestezi uygulamaları ve komplikasyonlar açısından değerlendirildi. Bulgular: Çalışmamızda başarısız işlem sıklı̆ıının yaşla birlikte artı̆ı̆ı ve yaşla birlikte normal işlem sıklığının azaldığı saptandı. Pankreatikobilier malignite siklığının yaşla birlikte arttı̆ı saptandı. Anestezi esnasında oluşan hipoksi komplikasyonunun yaşla birlikte arttığı ve post endoskopik retrograd kolanjiopankreatografi pankreatit sıklığı açısından gruplar arasında anlamlı fark olmadığı saptandı. Sfinkterotomi işlemine bağlı kanama komplikasyonunun yaşla birlikte arttığı saptandı. Sonuç: Endoskopik retrograd kolanjiopankreatografinin yaşl hastalarda güvenilir ve etkin bir yöntem olduğunu ancak yaşlı hastalarda komplikasyonlar açısından klinisyenin daha dikkatli davranması gerektiğini düşünüyoruz.
\end{abstract}

Anahtar kelimeler: Yaşlı hastalar, endoskopik retrograd kolanjiopankreatografi, etkinlik, güvenilirlik

\section{GİRIS}

Endoskopik işlemler, tüm yaş gruplarında gastrointestinal sistemin ve pankreatikobiliyer sistemin değerlendirilmesi ve tedavi edilmesi amacıyla kullanılmaktadır. Yaşlı hastalarda tüm endoskopik işlem teknikleri kullanılabilir ancak bu hastalarda oluşabilecek komplikasyonlar daha şiddetli olacağı için endoskopistin bu hastalara endoskopi planlarken daha dikkatli olması gerekir. Sonuç olarak, klinisyen kötü prognoz beklenen veya genel durumu kötü hastalarda, önerdiği endoskopik işlemin tanısal ve terapötik faydasını iyi değerlendirmelidir $(1,2)$. Yaşlı hastalarda yandaş hastalıkların sıklığı ve yaşa bağlı problemler tanı ve tedaviye yönelik girişimsel işlemleri komplike hale getirebilir (3).

Koledokolitiazis, pankreas başı kanseri ve safra yolu tümörleri gibi patolojilerin yaşlı hastalarda daha sık görülmesi nedeni ile bu hastalarda endoskopik retrograd kolanjiopankreatografi (ERCP) sıklıkla kullanılmaktadır. Hastalarda ERCP işlemine bağlı sfinkterotomi yerinden kanama, post-ERCP
Background/aims: There is a little data in the literature about the efficacy and safety of endoscopic retrograde cholangiopancreatography in elderly patients. We have evaluated the efficacy, safety and success rate of endoscopic retrograde cholangiopancreatography in elderly patients. Materials and Methods: Patients who were udergone endoscopic retrograde cholangiopancreatography between 2006-2010 years in Izmir Atatürk Education and Researc Hospital, were evaluated retrospectively. We investigated the diagnosis, success rate and complication rate of both endoscopic retrograde cholangiopancreatography and anesthesia. Results: We showed that unsuccesful endoscopic retrograde cholangiopancreatography rate increased and reporting normal endoscopic retrograde cholangiopancreatography decreased with age. Pancreaticobiliary tumor frequency and hipoxemia due to anesthesia increased with age. There was no difference regarding the risk of pancreatitis due to endoscopic retrograde cholangiopancreatography. Hemorrhage rate due to sphincteratomy increased with age. Conclusion: Endoscopic retrograde cholangiopancreatography is a safe and effective technique in elderly patients but endoscopists should be more careful about complications in elderly patients.

Key words: Elderly patients, endoscopic retrograde cholangiopancreatography, efficacy, safety

pankreatit gibi komplikasyonların yanında, anesteziye bağlı hipoksi, hipotansiyon ve aritmi gibi komplikasyonlar görülebilir. Ancak yaşlı hastalarda ERCP işleminin etkinliği ve güvenilirliğine yönelik sınırlı sayıda çalışma mevcuttur. 80 yaş üstü ve altı hastalarda ERCP işleminin güvenilirliğinin değerlendirildiği bir çalışmada işlem başarısı ve komplikasyon oranları açısından gruplar arasında fark saptanmamıştır (4). 90 yaş üstü ve 70-90 yaş arası hastalarda ERCP işlemi karşılaştırılmış ve 90 yaş üstü grupta yandaş hastalık sıklığı daha yüksek olmasına rağmen ERCP sonrası erken komplikasyon oranları benzer saptanmıştır (5).

Bu çalışmada yaşlı hastalarda ERCP işleminin etkinliği, güvenilirliği ve işlem başarı oranlarını değerlendirdik.

\section{GEREC ve YÖNTEM}

İzmir Atatürk Eğitim ve Araştırma Hastanesi Gastroenteroloji Kliniği'nde, 2006-2010 yılları arasında ERCP yapılan hastalar 
retrospektif olarak değerlendirildi. Hastaların demografik, laboratuar ve tedavi ile ilgili verileri hastane bilgi işlem veri tabanından, endoskopik verileri endoskopi laboratuvarı kayıtlarından elde edildi.

ERCP işlemi Olympus Exera 2 CV145 standart terapötik duodenoskop ile yapıldı. 3142 ERCP işlemi retrospektif olarak değerlendirildi. Hastalar 45-65 yaş, 65-80 yaş arası ve 80 yaş üzeri olacak şekilde 3 gruba ayrıldı. Hastalar tanı, işlem etkinliği, işlem başarısı, anestezi uygulamaları ve komplikasyonlar açısından değerlendirildi.

\section{BULGULAR}

Çalışmamızda ERCP yapılan 45-65 yaş arası 1000 hasta, 6580 yaş arası 1500, 80 yaş ve üzeri 642 hasta olmak üzere toplam 3142 hasta değerlendirildi. Gruplar tanı ve hastalık prevalansları, işlem başarısı (Tablo 1), işleme ve anesteziye bağlı komplikasyonlar açısından karşılaştırıldı (Tablo 2). Bizim çalışmamızda başarısız işlem sıklığının yaşla birlikte arttığı ve 40-65 yaş grubunda diğer iki gruba göre daha düşük oranda olduğu saptandı ( $<<0.001,0,001$, Grup 1-3, Grup 1-2, sırasıyla). Ayrıca yaşla birlikte normal işlem sıklığının azaldığı saptandi ( $<<0.001,0,001$, Grup 1-3, Grup 1-2, sirasiyla). Çalışmamızda pankreatikobilier malignite sıklığının yaşla birlikte arttığı ve 80 yaş üstü grupta diğer iki gruba göre anlamlı düzeyde yüksek olduğu görüldü $(\mathrm{p}<0.001,0,001,0.001$ Grup 1-3, Grup 1-2, Grup 2-3, sirasiyla), (Tablo 1). Anestezi esnasında oluşan hipoksi komplikasyonunun yaşla birlikte arttığı ve 40-65 yaş grubunda diğer iki gruba göre daha düşük olduğu saptandı (p<0.001, 0,001, Grup 1-3, Grup 1-2, sırasıyla). Post ERCP pankreatit sıklığı açısından gruplar arasinda anlamlı fark saptanmadı. Benzer şekilde sfinkterotomi işlemine bağlı kanama komplikasyonunun yaşla birlikte arttığ1 ve 40-65 yaş grubunda diğer iki gruba göre daha düşük olduğu saptand ( $(p<0.001,0,001$, Grup 1-3, Grup 1-2, sirasiyla). Ancak anesteziye bağl hipoksi ve sfinkterotomiye bağlı kanama oranı açısından 65-80 yaş grubu ile 80 yaş üstü grup arasında fark saptanmadi (Tablo 2).

\section{TARTISSMA}

Ortalama yaşam süresinin artması nedeniyle yaşlı hastalarda endoskopik inceleme sıklığı artmaktadır. Hastalık prevalanslarındaki farklılıklar, eşlik eden sistemik hastalıklar, ortaya çıkabilecek komplikasyonların sıklığı yaşlılarda endoskopik prosedürlerin daha dikkatli değerlendirilmesi ihtiyacını ortaya koymaktadır. Çalışmamızda kliniğimizde gerçekleştirilen ERCP işlemlerinin sonuçlarını değerlendirdik.

80 yaş üstü hastalarda biliyer cerrahi \%9,5 mortalite ve \%62 komplikasyon oranına sahiptir (6). ERCP yaşlı popülasyonda pankreatikobilier hastalıkların tanısında ve ana safra kanalının koledokolitiazis veya maligniteye bağlı obstrüksiyonun tedavisinde giderek artan oranda kullanılmaktadır. Yaşlı has-

\begin{tabular}{|c|c|c|c|}
\hline & $\begin{array}{c}\text { Grup } 1 \\
(45-65 \text { yaş) } \\
n=1000(\%)\end{array}$ & $\begin{array}{c}\text { Grup } 2 \\
(65-80 \text { yaş) } \\
n=1500(\%)\end{array}$ & $\begin{array}{c}\text { Grup } 3 \\
(>80 \text { yaş }) \\
n=642(\%)\end{array}$ \\
\hline Koledokolitiazis & $48.6^{\wedge \wedge \wedge}$ & $42.6+\uparrow \dagger$ & $36.0 *$ \\
\hline Pankreatikobilier malignite & $5.3^{\wedge \wedge \wedge}$ & $12.4+\dagger \dagger$ & $18.3 * * *$ \\
\hline Normal tetkik & $8.2^{\wedge \wedge \wedge}$ & $6.8+\dagger \dagger$ & 5.6 \\
\hline Başarısız işlem & $3.0^{\wedge \wedge \wedge}$ & $4.0++\dagger$ & 5.6 \\
\hline $\begin{array}{l}\text { Grup } 1 \text { ve } 2 \text { için, } \dagger: p<0.05 \\
\text { Grup } 2 \text { ve } 3 \text { için, * : p }<0.05 \\
\text { Grup } 1 \text { ve } 3 \text { için, }{ }^{\wedge}: p<0.05\end{array}$ & $\begin{array}{l}\dagger \dagger: \mathrm{p}<0.05-0.01 \\
* *: \mathrm{p}<0.05-0.01 \\
\wedge: \mathrm{p}<0.05-0.01\end{array}$ & $\begin{array}{l}\dagger \dagger \dagger: \mathrm{p}<0.001 \\
* * *: \mathrm{p}<0.001 \\
\wedge \wedge \wedge: \mathrm{p}<0.001\end{array}$ & \\
\hline
\end{tabular}

\begin{tabular}{|c|c|c|c|}
\hline & $\begin{array}{c}\text { Grup } 1 \\
(45-65 \text { yaş) } \\
n=1000(\%)\end{array}$ & $\begin{array}{c}\text { Grup } 2 \\
(65-80 \text { yaş) } \\
n=1500(\%)\end{array}$ & $\begin{array}{c}\text { Grup } 3 \\
(>80 \text { yaş }) \\
\mathrm{n}=642(\%)\end{array}$ \\
\hline Hipoksi & $2.8^{\wedge \wedge \wedge}$ & $3.2+\dagger \dagger$ & 3.7 \\
\hline Ami & 0.1 & 0.1 & 0.0 \\
\hline Kanama & $2.0^{\wedge \wedge \wedge}$ & $2.8+\dagger \dagger$ & 3.1 \\
\hline Perforasyon & 0.2 & 0.1 & 0.3 \\
\hline Post ERCP pankreatit & 1.6 & 1.1 & 0.3 \\
\hline Dormicum/Genel anestezi & $286 / 714$ & $462 / 1038$ & $156 / 486$ \\
\hline $\begin{array}{l}\text { Grup } 1 \text { ve } 2 \text { için, } \dagger: p<0.05 \\
\text { Grup } 2 \text { ve } 3 \text { için, }{ }^{*}: \mathrm{p}<0.05 \\
\text { Grup } 1 \text { ve } 3 \text { için, }{ }^{\wedge}: \mathrm{p}<0.05\end{array}$ & $\begin{array}{l}\dagger \dagger: \mathrm{p}<0.05-0.01 \\
* *: \mathrm{p}<0.05-0.01 \\
\wedge: \mathrm{p}<0.05-0.01\end{array}$ & $\begin{array}{l}\dagger \dagger \dagger: \mathrm{p}<0.001 \\
* * *: \mathrm{p}<0.001 \\
\wedge \wedge \wedge: \mathrm{p}<0.001\end{array}$ & \\
\hline
\end{tabular}

talarda ERCP’nin güvenilirliğini ve etkinliğini değerlendiren sınırlı sayıda çalışma vardır. 80 yaş üstü ve altı hastalarda ERCP işlemi karşılaştırılmış ve başarı oranı 80 yaş üstü hastalarda, \%88, 80 yas altı hastalarda \%86, komplikasyon oranı \%6.8'e karşı \%5.1 saptanmış ve istatistiksel olarak anlamlı fark saptanmamıştır (7). Bir başka çalışmada ise 90 yaş üstü hastalar ile 70-90 yaş arasındaki hastalarda ERCP işlemi karşılaştırılmış, erken komplikasyon oranı 90 yaş üzeri hastalarda \%6.3, 70-90 yaş arası hastalarda \%8.4 bulunmuştur. ERCP'ye bağlı mortalite oranı 90 yaş üzeri hastalarda \%1.6, 70-90 yaş arası hastalarda \%0.6 olarak saptanmıştır (5). Biz çalışmamızda başarısız işlem sıklığının yaşla birlikte artığını ve 40-65 yaş grubunda diğer iki gruba göre daha düşük olduğunu saptadık. Ayrıca yaşla birlikte normal işlem sıklığının azaldığını saptadık. Çalışmamızda pankreatikobilier malignite sıklığının yaşla birlikte arttığı ve 80 yaş üstü grupta diğer iki gruba göre anlamlı düzeyde yüksek olduğunu gördük.

Genç hastalarda olduğu gibi yaşlı hastalarda da sedatif ajanlarla farklı etkiler görülebilir. Yaşlı hastalar hipoksi, hipotansiyon ve aritmiye daha eğilimlidir (1-2-8). Çalışmamızda anestezi esnasında oluşan hipoksi komplikasyonunun yaşla birlikte arttı̆̆ını ve 40-65 yaş grubunda diğer iki gruba göre daha düşük olduğu saptadık. 80 yaş üstü ve altı hastalarda sfinkterotomi işlemine bağlı kanama komplikasyonu benzer saptanmıştır (\%4.l'e karşı \%4.3) (4). Biz çalışmamızda 40-65 
yaş grubunda sfinkterotomi işlemine bağlı kanama komplikasyonu sıklığının diğer iki gruba göre daha düşük olduğunu saptadık. Ancak çalışmamızda hipoksi ve kanama komplikasyonları açısından 65-80 yaş grubu ile 80 yaş üstü grup arasında fark saptamadık. ERCP işleminin yaşlı hastalarda etkin ve güvenilir bir işlem olduğunu ancak işleme ve anesteziye bağlı komplikasyonlar açısından yaşlı hastalarda 65 yaş altı hastalara göre daha dikkatli olunması gerektiği sonucuna vardık.
Sonuç olarak, yaşla birlikte safra yolları ve pankreas kanserinin artıyor olması ve bu hastalarda cerrahi müdahalenin yüksek mortalite ve morbidite göstermesi nedeniyle, ERCP işlemi yaşlı hastaların tanı ve tedavisinde önemli yeri olan bir işlemdir. ERCP'nin yaşlı hastalarda güvenilir ve etkin bir yöntem olduğunu ancak yaşlı hastalarda komplikasyonlar açısından klinisyenin daha dikkatli davranması gerektiğini düşünüyoruz.

\section{KAYNAKLAR}

1. Modifications in endoscopic practise for the elderly. American Society for Gastrointestinal Endoscopy. Gastointest Endosc 2000;52:849-51.

2. Qureshi WA, Zuckerman MJ, Adler DG, et al. Standarts of Practise Committee ASGE guideline: modifications in endoscopic practise fort the elderly. Gastointest Endosc 2006;63:566-9.

3. Rubenstein LZ, Rubenstein LV. Comprehensive geriatric assesment of older patients with gastrointestinal disorders. In: Pilotto A, Maltertheiner P, Holt PR, Editors. Aging and the Gastrointestinal Tract. Interdiscip Top Gerontol. Basel, Karger. Vol. 32, 2003:12-27.

4. Riphaus A, Stergiou N, Wehrmann T. ERCP in octogenerians: a safe and efficient investigation. Age Ageing 2008;37:595-9.

5. Katsinelos P, Paroutoglou G, Kountouras J, et al. Efficacy and safety of therapeutic ERCP in patients 90 years of age and older. Gastrointest Endosc 2006;63:417-23.

6. Sullivan DM, Hood TR, Griffen WO Jr. Biliary tract surgery in the elderly. AM J Surg 1982;143:218-20.

7. Fritz E, Kirchgatterer A, Hubner D, et al. ERCP is safe and effective in patients 80 years of age and older compared with younger patients. Gastrointest Endosc 2006;64:899-905.

8. Ekstein M, Gavish D, Ezri T, Weinbroumm AA. Monitored anaesthesia care in the elderly: guidelines and recommendations. Drugs Aging 2008:25:477-500 